\title{
Subcutaneous bone flap storage after emergency craniectomy: cost-effectiveness and rate of resorption
}

\author{
Griffin Ernst, MD, ${ }^{1}$ Fares Qeadan, PhD, ${ }^{2}$ and Andrew P. Carlson, MD, MS-CR ${ }^{3}$ \\ 1University of New Mexico School of Medicine; ${ }^{2}$ Clinical and Translational Science Center; and ${ }^{3}$ Department of Neurosurgery, \\ University of New Mexico School of Medicine, Albuquerque, New Mexico
}

\begin{abstract}
OBJECTIVE Decompressive craniectomy is used for uncontrolled intracranial pressure in traumatic brain injury and malignant hemispheric stroke. Subcutaneous preservation of the autologous bone flap in the abdomen is a simple, portable technique but has largely been abandoned due to perceived concerns of resorption. The authors sought to characterize their experience with subcutaneous preservation of the bone flap and cranioplasty.
\end{abstract}

METHODS The authors performed a retrospective single-institution review of subcutaneous preservation of the autologous bone flap after decompressive craniectomy from 2005 to 2015. The primary outcome was clinically significant bone resorption, defined as requiring a complete mesh implant at the time of cranioplasty, or delayed revision. The outcome also combined cases with any minor bone resorption to determine predictors of this outcome. Logistic regression modeling was used to determine the risk factors for predicting resorption. A cost comparison analysis was also used via the 2-sided t-test to compare the cost of cranioplasty using an autologous bone flap with standard custom implant costs.

RESULTS A total of 193 patients with craniectomy were identified, 108 of whom received a cranioplasty. The mean time to cranioplasty was 104.31 days. Severe resorption occurred in 10 cases (9.26\%): 4 were clinically significant (2 early and 2 late) and 6 demonstrated type II (severe) necrosis on CT, but did not require revision. Early resorption of any kind (mild or severe) occurred in 28 (25.93\%) of 108 cases. Of the 108 patients, $26(24.07 \%)$ required supplemental cranioplasty material. Late resorption of any kind (mild or severe) occurred in $6(5.88 \%)$ of 102 cases. Of these, a clinically noticeable but nonoperative deformity was noted in 4 (3.92\%) and minor (type I) necrosis on CT in 37 (37\%) of 100. Bivariate analysis identified fragmentation of bone (OR 3.90, 95\% Cl 1.03-14.8), shunt-dependent hydrocephalus (OR 7.97, $95 \% \mathrm{Cl} 1.57-40.46$ ), and presence of post-cranioplasty drain (OR 9.39, 95\% Cl 1.14-1000) to be significant risk factors for bone resorption. A binary logistic regression optimized using Fisher's scoring determined the optimal multivariable combination of factors. Fragmentation of bone (OR 5.84, 95\% Cl 1.38-28.78), diabetes (OR 7.61, 95\% Cl 1.37-44.56), and shunt-dependent hydrocephalus (OR 9.35, 95\% $\mathrm{Cl} 1.64-56.21$ ) were found to be most predictive of resorption, with a C value of 0.78 . Infections occurred in the subcutaneous pocket in $5(2.60 \%)$ of the 193 cases and after cranioplasty in $10(9.26 \%)$ of the 108 who underwent cranioplasty. The average cost of cranioplasty with autologous bone was $\$ 2156.28$ $\pm \$ 1144.60(n=15)$, and of a custom implant was $\$ 35,118.60 \pm \$ 2067.51$ (3 different sizes; $p<0.0001$ ).

CONCLUSIONS Craniectomy with autologous bone cranioplasty using subcutaneous pocket storage is safe and compares favorably to cryopreservation in terms of resorption and favorably to a custom synthetic implant in terms of cost. While randomized data are required to definitively prove the superiority of one method, subcutaneous preservation has enough practical advantages with low risk to warrant routine use for most patients.

https://thejns.org/doi/abs/10.3171/2017.6.JNS17943

KEY WORDS subcutaneous pocket; cranioplasty; bone resorption; autologous bone

$\mathrm{D}$ ECOMPRESSIVE craniectomy has regained popularity over the past few decades. ${ }^{18}$ Primarily used in the setting of traumatic brain injury (TBI $)^{24,31}$ and ischemic stroke, ${ }^{35,37}$ it has also been used in the management of dural sinus thrombosis, ${ }^{13}$ subarachnoid hemor- rhage, ${ }^{14}$ intracranial infection, ${ }^{1}$ and severe inflammation. ${ }^{10}$ Once the life-threatening swelling has subsided, surviving patients require cranioplasty to avoid various long-term complications..$^{20}$ Several materials can be used when performing a cranioplasty, ranging from the patient's own

ABBREVIATIONS COPD = chronic obstructive pulmonary disease; $\mathrm{MI}=$ myocardial infarction; MRSA = methicillin-resistant Staphylococcus aureus; $\mathrm{TBI}=$ traumatic brain injury.

SUBMITTED April 13, 2017. ACCEPTED June 19, 2017.

INCLUDE WHEN CITING Published online January 5, 2018; DOI: 10.3171/2017.6.JNS17943. 
bone flap to custom-designed implants.,12,16 Autologous bone flaps can be stored either in a subcutaneous pocket or through cryopreservation in a freezer. ${ }^{8,23}$ The benefits of using an autologous bone flap are its low cost, the implant is matched with the patient, and because it is derived from the patient, there is no concern for rejection. In addition, patients whose bone is stored in a subcutaneous pocket avoid the logistical difficulties of having a cranioplasty performed at another institution. Also, institutions do not have to maintain biological freezer banks, further reducing cost and potential interpatient specimen confusion. However, subcutaneous pocket storage does not appear to be as common as cryopreservation, with some advocating for cryopreservation citing greater mechanical loading force of a frozen flap and the need for only 1 incision site. ${ }^{43}$

Despite the simplicity of the procedure, a number of reported complications including infection and aseptic bone resorption have prompted a review of the technique by various institutions. $3,4,7,11,15,20,25-27,32-34,40,42$ Bone resorption is often cited as a complication of autologous cranioplasty, however, much of the research performed makes use of cryopreservation $^{4,7,11,15,20-22,33,34,36,40,41}$ as compared with subcutaneous pocket storage ${ }^{28,29,38}$ and even fewer studies have compared the two directly. ${ }^{8,17}$ Several articles have, in fact, described some mechanisms by which cryopreservation may lead to higher rates of resorption versus subcutaneous pocket storage..$^{28,38}$

In the military, craniectomy practice has shifted to essentially exclusively discarding bone flaps with later placement of custom cranioplasty. ${ }^{6}$ While this certainly may be reasonable in cases of open, contaminated, or fragmented wounds, significant additional cost of the cranioplasty is incurred, possibly coupled with further delay in cranioplasty, which can impair recovery from severe TBI. ${ }^{2}$

Over the past decade, it has been our first-line practice in cases of craniectomy to attempt autologous bone cranioplasty with subcutaneous preservation. We sought to characterize the rates of immediate and delayed resorption, infection, and cost of craniectomy to be compared with published rates of cryopreservation and custom cranioplasty.

\section{Methods}

We conducted a retrospective chart review, approved by the IRB at the University of New Mexico Hospital, which has been the only Level 1 trauma center and advanced primary stroke center in New Mexico during the study period.

\section{Inclusion Criteria}

We included all patients requiring a decompressive craniectomy who subsequently had undergone attempted cranioplasty. We excluded patients who did not undergo cranioplasty because of death or being lost to follow-up.

\section{Surgical Procedure (standard of care)}

Standard surgical technique was used when performing a craniectomy and later cranioplasty. During the craniectomy the abdomen was prepared and draped in the usual sterile manner. Large craniotomies were performed with stellate dural opening in all cases and brain resection as required to prevent gross herniation through the defect. A dural onlay substitute was placed over the brain and dura to aid in later separation of the flap. An incision was made in a lower quadrant of the abdomen (left was preferred) and a suprafascial pocket created with blunt dissection and electrocautery. Typically, the bone was placed in 1 piece. If the bone was fragmented by fracture or if the patient was very small, the bone was placed in the abdomen in 2-3 pieces. For cranioplasty, the abdomen was typically opened first to rule out infection. If unexpected abdominal infection was encountered, the procedure was either terminated or the abdominal field was isolated from the cranial field by redraping the abdominal portion out of the field and removing contaminated instruments. Cranioplasty was performed with precontoured hemicranial mesh. After retrieval, the bone was replated into the defect using a standard plating system. In some cases, dural tackup sutures were placed through the flap and in some cases, multiple perforations were made in the flap and a subgaleal Jackson-Pratt drain was placed. If it was believed that there was a significant defect in the bone coverage, the attending surgeon would either place mesh or hydroxyapatite cement to cover the defect, or if the bone resorption was very severe, a complete preformed hemicranial mesh was used. This decision was up to the attending surgeon. Multiple surgeons performed these procedures during the time of the study.

\section{Data Acquisition}

Patients were identified by the CPT code and all charts were individually reviewed to determine if they met the inclusion criteria. Clinical data related to infection and resorption were recorded as well as risk factors previously identified in the literature for bone resorption. These risk factors included shunt-dependent hydrocephalus, fragmentation into 2 or more fragments, ${ }^{11,34}$ tobacco use, ${ }^{42}$ chronic obstructive pulmonary disease (COPD), diabetes, previous myocardial infarction (MI), sex, perforations for tack-up sutures, post-cranioplasty drain, age at craniectomy, size of defect, and length of time to cranioplasty. The size of the craniotomy defect was determined using axial CT images obtained at subsequent hospital encounters. We used the formula $\mathrm{A}=(\pi / 4) \times \mathrm{B} \times \mathrm{b}$ to calculate the area of an ellipse as previously described, where $\mathrm{B}$ is the maximum length from one edge of the craniotomy to another, and $b$ was calculated by number of slices of the CT scan multiplied by the width of each slice. ${ }^{11,36}$

\section{Primary Outcome}

Our primary outcome was severe bone resorption. Severe resorption was determined at 2 stages, early and late. Early severe resorption was defined as the need for complete hemicranial synthetic mesh at the time of cranioplasty. Late severe resorption was defined as the patient needing a revision due to bone resorption or type II necrosis as defined by circumscribed complete lysis of the bone flap, including the tabula interna and externa as noted on CT.11,36 This method was used to compare with previous publications. 


\section{Secondary Outcome}

Secondary measures included any bone resorption and infection. More mild resorption cases were also defined as early and late. Early mild resorption was defined as requiring additional peripheral mesh coverage or other cranioplasty material at the time of cranioplasty. Late mild resorption was defined as cosmetic deformity noted by the physician or patient or type I necrosis on CT and/or thinning along the rims of the bone flap, $, 11,36$ but not requiring revision. Infection rate included either infections occurring while the bone flap was stored in the abdomen or any infection of the bone flap after cranioplasty. In addition, a cost analysis was performed, comparing the actual operating room supply charges for implants for our cases of cranioplasty to the cost to our institution of the most commonly used custom cranioplasty. There are tiered costs for these implants depending on size, so all 3 sizes were considered.

\section{Statistical Analysis}

Several patient characteristics were used to assess potential risk factors for resorption. These risk factors include diabetes, sex, fragmentation of bone into 2 or more pieces, perforations for tack-up sutures, post-cranioplasty drain, age at craniectomy, size of defect, tobacco use, and length of time to cranioplasty. We used a bivariate logistic regression analysis to determine which of these characteristics was significantly associated with severe bone resorption. Following that, a multiple logistic regression model optimized with Fisher's scoring was used to ascertain the optimal multivariate combination of factors to predict severe resorption of any kind (early plus late). The area under the receiver operating characteristic, denoted by the $\mathrm{C}$ value, was used to assess the discrimination power of the conducted logistic regression models. ${ }^{30}$ Significance of the

\section{Patients Identified}

\begin{tabular}{|l|}
$45(23 \%)$ died \\
$6(3.1 \%)$ lost to follow up \\
$5(2.6 \%)$ had bone flap \\
discarded due to abdominal \\
site infection \\
$29(15 \%)$ had bone discarded \\
for other reasons (multiple \\
fragments, contaminated, etc)
\end{tabular}

\section{Patients \\ Received Cranioplasty}

FIG. 1. Flow chart detailing the reasons why some patients did not receive cranioplasty.
TABLE 1. Demographics of the study population

\begin{tabular}{lc}
\hline \multicolumn{1}{c}{ Variable } & Value \\
\hline Demographics & \\
\hline No. of patients & 108 \\
\hline Median age in yrs (IQR) & $36(1-66)$ \\
\hline Female, no. (\%) & $39(36)$ \\
\hline Male, no. (\%) & $69(64)$ \\
\hline Shunt-dependent hydrocephalus, no. (\%) & $8(7)$ \\
\hline Diabetes, no. (\%) & $12(11)$ \\
\hline Tobacco use, no. (\%) & $21(19)$ \\
\hline COPD, no. (\%) & $2(2)$ \\
\hline Neoplasm, no. (\%) & $4(4)$ \\
\hline Prior MI, no. (\%) & $2(2)$ \\
\hline Average time to cranioplasty, days & 104 \\
\hline Average length of follow-up, days & 348 \\
\hline Multiple perforations in bone flap, no. (\%) & $31(29)$ \\
\hline Post-cranioplasty drain, no. (\%) & $78(72)$ \\
\hline Indications for craniectomy & $26(24)$ \\
\hline Ischemic stroke, no. (\%) & $5(5)$ \\
\hline Other spontaneous intracerebral bleed, no. (\%) & $7(6)$ \\
\hline Aneurysmal subarachnoid hemorrhage, no. (\%) & $39(36)$ \\
\hline TBI, no. (\%) & $2(2)$ \\
\hline Tumor, no. (\%) & $2(25)$ \\
\hline Extraaxial bleed, no. (\%) & \\
\hline Other, no. (\%) & \\
\hline
\end{tabular}

$\mathrm{IQR}=$ interquartile range.

cost analysis was established by a 2-sided t-test. All statistical analyses were performed using SAS (version 9.4, SAS Institute Inc.). For all analyses, we used an a priori $\alpha$ of 0.05 to determine statistical significance.

\section{Results}

A total of 193 patients who received craniectomies were identified. Of those 193 patients, 85 did not receive cranioplasty, leaving 108 patients available for analysis (Fig. 1). Patient and surgical characteristics are detailed in Table 1 . The primary indication for craniectomy was TBI. The average time to cranioplasty was $104 \pm 70$ days, and patients were followed for an average of 348 days (range 1-3305 days).

\section{Primary and Secondary Outcomes}

Resorption results are listed in Table 2. Severe resorption (early or late) occurred in 10 cases $(9.26 \%)$. Only 2 $(1.85 \%)$ of these 108 cases were early, requiring complete synthetic cranioplasty. In the delayed group, 2 (1.96\%) of 106 cases also required redo cranioplasty due to resorption. The remaining 6 cases had type II necrosis on CT but did not require cranioplasty revision. Early resorption of any kind, while the bone flap was secured within the subcutaneous pocket, occurred in 28 cases $(25.93 \%)$ but typically required an additional piece of mesh or other material to cover existing gaps in the majority of cases. 
TABLE 2. Current series resorption rates

\begin{tabular}{lc}
\hline Resorption & Value (\%) \\
\hline Early severe & $2 / 108(1.85)$ \\
\hline Early mild & $26 / 108(24.07)$ \\
\hline Late severe & $2 / 106(1.96)$ \\
\hline Late mild & $4 / 106(3.92)$ \\
\hline Type I necrosis & $37 / 100(37.00)$ \\
\hline Type II necrosis & $6 / 100(6.00)$ \\
\hline
\end{tabular}

Delayed resorption of any kind following cranioplasty occurred in 6 cases. This was severe enough to require a redo of the cranioplasty in 2 cases (above), and only resulted in cosmetic deformity noted by the physician or patient in $4(3.92 \%)$ of 102 cases. CT scans after cranioplasty were available in 100 patients. Type I necrosis was noted in 37 patients (37\%) and type II necrosis was observed in 6 patients $(6 \%)$, but these did not all require a revision.

Infections occurred in the abdominal subcutaneous pocket in $5(2.60 \%)$ of the 193 cases and consisted of Staphylococcus aureus and methicillin-resistant S.aureus (MRSA). Following cranioplasty there were a total of 10 patients $(9.3 \%)$ who developed an infection consisting of 2 cases of Pseudomonas aeruginosa; 1 case each of Propionibacterium acnes, MRSA, Enterobacter aerogenes, mixed anaerobic, Streptococcus pyogenes, and Enterobacter cloacae; and 1 patient whose culture demonstrated both S. epidermidis and P. acnes (Table 3). In all of these cases, the bone flap was removed and replaced in a delayed custom cranioplasty after completion of antibiotic therapy.

\section{Potential Risk Factors}

We then attempted to determine factors that were implicated in any degree of bone resorption, which was defined as a need for: 1) material to supplement closure or an entirely new synthetic implant at the time of cranioplasty; 2) revision or physician/patient complaint; or 3) type I/II necrosis on CT following cranioplasty. Using bivariate analysis, we examined 11 risk factors that we believed could potentially contribute to increased risk of bone resorption including diabetes, sex, fragmentation of bone, indication for craniectomy, multiple perforations for tack-up sutures, past cranioplasty drain, shunt-dependent

TABLE 3. Infections

\begin{tabular}{lc}
\hline \multicolumn{1}{c}{ Infections } & No. of Patients \\
\hline Total, after cranioplasty & $10(9.3 \%)$ \\
\hline P. aeruginosa & 2 \\
\hline P. acnes & 2 \\
\hline MRSA & 1 \\
\hline E. aerogenes & 1 \\
\hline Mixed anaerobic & 1 \\
\hline S. pyogenes & 1 \\
\hline S. epidermidis & 1 \\
\hline E. cloacae & 1 \\
\hline
\end{tabular}

TABLE 4. Factors predicting severe resorption in multivariate analysis

\begin{tabular}{lcc}
\hline \multicolumn{1}{c}{ Effect } & OR & $95 \% \mathrm{Cl}$ \\
\hline Fragmentation of bone & 5.84 & $1.38-28.78$ \\
\hline Diabetes & 7.61 & $1.37-44.56$ \\
\hline Shunt-dependent hydrocephalus & 9.35 & $1.64-56.21$ \\
\hline
\end{tabular}

hydrocephalus, age at craniectomy, size of defect, tobacco use, and length of time to cranioplasty. Of these, only fragmentation of bone (OR 3.90, 95\% CI 1.03-14.8), shuntdependent hydrocephalus (OR 7.97, 95\% CI 1.57-40.46), and presence of post-cranioplasty drain (OR 9.39, 95\% CI 1.14-1000) were found to be statistically significant. Binomial multiple logistic regression optimized using Fisher's scoring was then used to determine the optimal multivariable combination of factors to predict severe resorption. Fragmentation of bone (OR 5.84, 95\% CI 1.38-28.78), diabetes (OR 7.61, 95\% CI 1.37-44.56), and shunt-dependent hydrocephalus (OR 9.35, 95\% CI 1.64-56.21) were found to be most predictive of resorption with a $\mathrm{C}$ value of 0.78 (Table 4).

\section{Cost Analysis}

Fifteen patients were selected for a cost analysis based on available complete charge data from the operating room. The average cost for disposables of an autologous cranioplasty was $\$ 2156.28 \pm \$ 1144.60$. This analysis did not include professional or other fees because these were expected to be similar between autologous and custom cranioplasty. We then averaged the cost of custom cranioplasty using our contracted supplier (Stryker CMF Medpor). The average cost of the 3 sizes of implants was $\$ 35,118.60 \pm \$ 2067.51$. This difference was statistically significant according to a 2 -sided t-test $(\mathrm{p}<0.0001)$.

\section{Discussion}

Our retrospective review is one of the largest studies examining the use of subcutaneously stored bone flaps for cranioplasty. Overall, we believe that autologous cranioplasty compares favorably to cryopreservation and routine custom synthetic cranioplasty in terms of resorption, infection, and cost. There are multiple practical benefits to this technique, including the portability of the flap if the patient goes to a different facility, the lack of need for maintaining a bone bank, and the low cost.

We have found that the rate of resorption in our study $(10 \%)$ was similar to those in previous studies using subcutaneous storage (2\%-7\%), $, 17,28,38$ and compares favorably to cryopreservation $(4 \%-50 \%)^{11,15,17,19,21,22,33,34,36,40,42}$ (Table 5). There are significant problems with standardization of the definition of resorption, and most of our cases of severe resorption were radiographic only (Fig. 2). Our early severe $(1.85 \%)$ and late severe $(1.96 \%)$ resorption rates appear quite favorable compared with those in the published data. A recent systematic review comparing cryopreservation with an abdominal pocket found similar resorption rates of $9.7 \%$ versus $7.7 \%$, respectively, using the 2 techniques. ${ }^{9}$ Interestingly, the cryopreservation group had 
TABLE 5. Reported bone resorption rates in the literature

\begin{tabular}{|c|c|c|}
\hline Authors \& Year & $\begin{array}{c}\text { No of. } \\
\text { Patients }\end{array}$ & $\begin{array}{c}\text { Reported } \\
\text { Bone } \\
\text { Resorption } \\
(\%)\end{array}$ \\
\hline \multicolumn{3}{|l|}{ Significant resorption (cryopreservation) } \\
\hline Dünisch et al., 2013 & 372 & 22.8 \\
\hline Grant et al., 2004 (pediatric study) & 40 & 50 \\
\hline Häuptli \& Segantini, 1980 & 143 & 16 \\
\hline Honeybul \& Ho, 2012 & 156 & 9 \\
\hline Honeybul et al., 2017 & 31 & 22 \\
\hline laccarino et al., 2015 & 31 & 6 \\
\hline Schoekler \& Trummer, 2014 & 45 & 18 \\
\hline Schuss et al., 2013 & 254 & 4 \\
\hline Schwarz et al., 2016 & $124 \& 460$ & $\begin{array}{l}10.4 \text { (early), } \\
21.5 \text { (late) }\end{array}$ \\
\hline Sundseth et al., 2014 & 47 & 4.3 \\
\hline Wachter et al., 2013 & 121 & 17.7 \\
\hline \multicolumn{3}{|c|}{ Significant resorption (subcutaneous pocket) } \\
\hline Movassaghi et al., 2006 & 49 & 2.04 \\
\hline Shoakazemi et al., 2009 & 89 & 2.25 \\
\hline Häuptli \& Segantini, 1980 & 42 & 7 \\
\hline Current series & 106 & 1.96 \\
\hline \multicolumn{3}{|c|}{ Nonsignificant resorption (cryopreservation) } \\
\hline Honeybul \& Ho, 2012 & 156 & 21 \\
\hline Honeybul \& Ho, 2011 & 64 & 22 \\
\hline \multicolumn{3}{|l|}{$\begin{array}{l}\text { Nonsignificant resorption (subcutaneous } \\
\text { pocket) }\end{array}$} \\
\hline Movassaghi et al., 2006 & 49 & 15 \\
\hline Current series & 106 & 3.92 \\
\hline
\end{tabular}

a higher rate of surgical reoperations at $15.9 \%$ compared with $7.6 \%$ of those stored in the abdominal pocket, but this difference was not statistically significant.

It has been postulated that the favorable bone resorption rate of subcutaneous pocket storage over cryopreservation
TABLE 6. Reported infection rates in the literature

\begin{tabular}{cc}
\hline Authors \& Year & Infection Rate (\%) \\
\hline Cryopreservation & \\
\hline Cheng et al., 2014 & 11.1 \\
\hline Inamasu et al., 2009 & 16.1 \\
\hline Matsuno et al., 2005 & 25.9 \\
\hline Morton et al., 2016 & 6.6 \\
\hline Subcutaneous pocket & 18.2 \\
\hline Cheng et al., 2014 & 5.1 \\
\hline Inamasu et al., 2009 & Pre-cranioplasty (2.55), post- \\
\hline Current series & cranioplasty (9.3) \\
\hline
\end{tabular}

is a result of the bone's ability to undergo remodeling once placed back on the skull due to the presence of viable cells maintained in the bone. The different storage methods provide varying levels of cells capable of performing remodeling, with sterilization and freezing being the least likely to preserve native bone cells. ${ }^{28,38,39}$ It is because of this that cryopreservation leads to greater levels of bone resorption once re-implanted. However, even this conclusion has been questioned by Sultan et al. who found that cellular architecture was better preserved when cryopreserved, although the study was conducted using an animal model with storage lasting only 10 days, with follow-up of 12 weeks. ${ }^{39}$

Another concern over subcutaneous pocket storage is the possibility of an increased infection rate stemming from a second incision site over the abdomen. However, we had only 5 patients $(2.60 \%)$ whose bone flap became infected within the abdominal pocket. These cases do not threaten the cranial incision and the bone can simply be removed and treated with antibiotics prior to custom synthetic cranioplasty. The overall infection rate of our cranioplasty procedures was higher than our overall institutional infection rate of $3 \%-6 \%$, but this is within the reported range for such procedures $(5 \%-25 \%$; Table 6), ${ }^{8,23,26,27}$ which is likely due to the fact that these are revi-
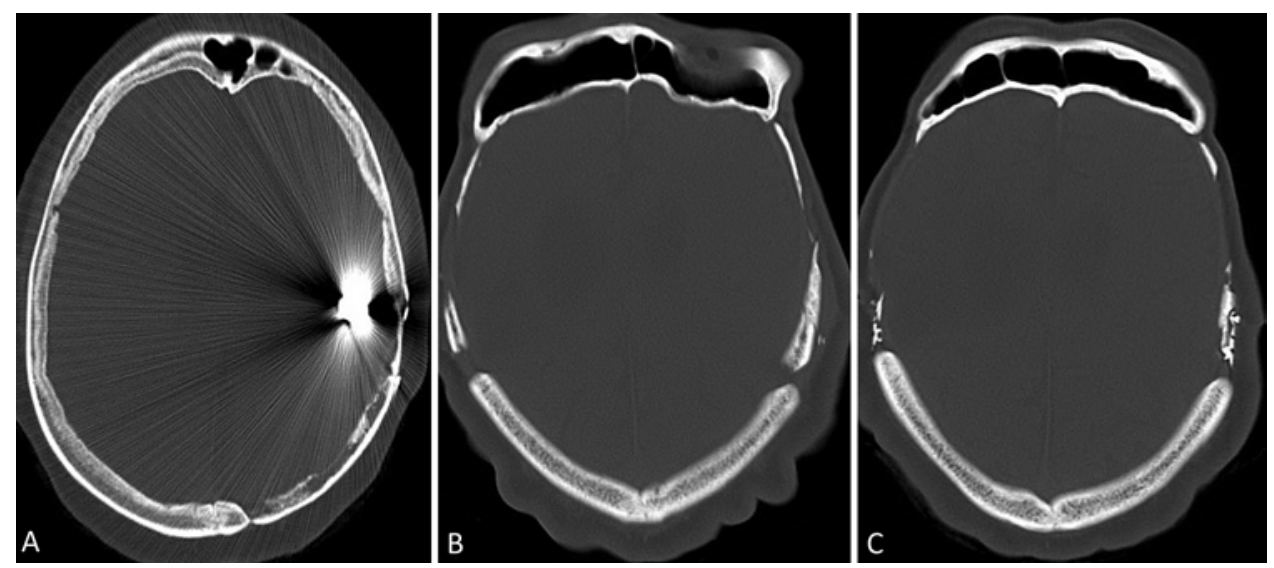

FIG. 2. Noncontrasted head CT scans show type I necrosis with resorption of the inner table, but preservation of the external table (A), and post-cranioplasty images demonstrating type II necrosis with resorption of the internal and external table (B) that worsened after 2 years $(\mathbf{C})$. 
sion surgeries to begin with and are uniformly performed in patients with significant neurological injury and other potential systemic risk factors. In the systematic review by Corliss et al., ${ }^{9}$ overall infection rates between cryopreservation and the abdominal pocket were similar at $7.3 \%$ and $7.1 \%$, respectively.

The risk factors we discovered to be relevant to resorption were relatively intuitive. Multiple fragments of bone certainly have a higher risk of resorption; if possible, dividing should be avoided. Yet, this did not occur uniformly and so an initial attempt at autologous bone preservation, even in cases of fracture fragments, may be reasonable to a point. Diabetes emerged as a risk factor as well as shunt-dependent hydrocephalus. The specific mechanism for these risk factors is not known but should be taken into consideration when considering cranioplasty.

The cost of performing an autologous cranioplasty is far more favorable than using a custom-made synthetic implant. Storing in a subcutaneous pocket also avoids the cost associated with maintaining a freezer bank for cryopreservation. While these costs are difficult to quantify on a per patient basis, we do not think that there is any theoretical cost offset with cryopreservation, thus subcutaneous storage likely compares favorably to all other methods.

This study has several limitations. There are inherent limitations of a retrospective review, although all other available data on this topic suffer from a similar limitation. A significant number of patients with craniectomy did not undergo cranioplasty, mostly due to death, but some were also lost to follow-up. While our severe outcomes were straightforward to quantify, the more moderate resorption defined by a need for additional mesh and delayed CT findings were more subjective. Some patients who required additional mesh may have had bone rongeured beyond the craniotomy at the time of craniectomy to increase the size of the craniectomy. The follow-up duration is relatively short and we do not have long-term data on either CT or cosmetic appearance of these flaps. While this is certainly a potentially significant issue, we believe that it is very unlikely that a significant number of patients sought care for revision of cranioplasty at other institutions due to the relatively centralized trauma and stroke care at our institution. Therefore, it is unlikely that there is a significant number of patients who required delayed redo cranioplasty that were missed by our study. In addition, the cost analysis is not straightforward because 15 of our patients did ultimately require synthetic cranioplasty. Yet one must consider that there is a significant infection rate in this population even with custom cranioplasty. Even if this infection rate is lower (this question has not been directly addressed to date), if such a custom cranioplasty would require removal, the patient would incur double the cost. It is therefore unlikely that there is a cost-effective model for initial custom cranioplasty based on the available data.

Finally, while subcutaneous storage is generally fairly benign, there is typically some discomfort regarding the flap in patients, especially those with little subcutaneous fat. While we did not note any cases of erosion of the flap requiring surgery apart from those with infection, we did not specifically review for other potential more minor complications regarding the abdominal pocket.
Despite these limitations, we believe that these data provide a modern experience to support the use of subcutaneous bone preservation with craniectomy in terms of resorption rates, comparable infection rates, and favorable cost profile. Caution may be warranted in patients with multiple bone fragments, diabetes, or shunt-dependent hydrocephalus for subcutaneous storage, and a consideration of initial synthetic cranioplasty may be appropriate.

\section{Conclusions}

Craniectomy with autologous cranioplasty stored in a subcutaneous pocket is safe and compares favorably to cryopreservation in terms of resorption and favorably to custom synthetic implant in terms of cost. While trials would be needed to confirm these conclusions definitively, we believe that for these practical and cost reasons, this procedure should be considered as the first-line treatment approach for craniectomy.

\section{References}

1. Agrawal D, Hussain N: Decompressive craniectomy in cerebral toxoplasmosis. Eur J Clin Microbiol Infect Dis 24:772-773, 2005

2. Ashayeri K, M Jackson E, Huang J, Brem H, R Gordon C: Syndrome of the trephined: a systematic review. Neurosurgery 79:525-534, 2016

3. Beauchamp KM, Kashuk J, Moore EE, Bolles G, Rabb C, Seinfeld J, et al: Cranioplasty after postinjury decompressive craniectomy: is timing of the essence? J Trauma 69:270274, 2010

4. Bobinski L, Koskinen LOD, Lindvall P: Complications following cranioplasty using autologous bone or polymethylmethacrylate - retrospective experience from a single center. Clin Neurol Neurosurg 115:1788-1791, 2013

5. Bonda DJ, Manjila S, Selman WR, Dean D: The recent revolution in the design and manufacture of cranial implants: modern advancements and future directions. Neurosurgery 77:814-824, 2015

6. Bonfield CM, Kumar AR, Gerszten PC: The history of military cranioplasty. Neurosurg Focus 36(4):E18, 2014

7. Bowers CA, Riva-Cambrin J, Hertzler DA II, Walker ML: Risk factors and rates of bone flap resorption in pediatric patients after decompressive craniectomy for traumatic brain injury. J Neurosurg Pediatr 11:526-532, 2013

8. Cheng CH, Lee HC, Chen CC, Cho DY, Lin HL: Cryopreservation versus subcutaneous preservation of autologous bone flaps for cranioplasty: comparison of the surgical site infection and bone resorption rates. Clin Neurol Neurosurg 124:85-89, 2014

9. Corliss B, Gooldy T, Vaziri S, Kubilis P, Murad G, Fargen K: Complications after in vivo and ex vivo autologous bone flap storage for cranioplasty: a comparative analysis of the literature. World Neurosurg 96:510-515, 2016

10. Di Rienzo A, Iacoangeli M, Rychlicki F, Veccia S, Scerrati $\mathrm{M}$ : Decompressive craniectomy for medically refractory intracranial hypertension due to meningoencephalitis: report of three patients. Acta Neurochir (Wien) 150:1057-1065, 2008

11. Dünisch P, Walter J, Sakr Y, Kalff R, Waschke A, Ewald C: Risk factors of aseptic bone resorption: a study after autologous bone flap reinsertion due to decompressive craniotomy. J Neurosurg 118:1141-1147, 2013

12. Feroze AH, Walmsley GG, Choudhri O, Lorenz HP, Grant GA, Edwards MSB: Evolution of cranioplasty techniques in neurosurgery: historical review, pediatric considerations, and current trends. J Neurosurg 123:1098-1107, 2015 
13. Ferro JM, Crassard I, Coutinho JM, Canhão P, Barinagarrementeria F, Cucchiara B, et al: Decompressive surgery in cerebrovenous thrombosis: a multicenter registry and a systematic review of individual patient data. Stroke 42:28252831, 2011

14. Fisher CM, Ojemann RG: Bilateral decompressive craniectomy for worsening coma in acute subarachnoid hemorrhage. Observations in support of the procedure. Surg Neurol 41:65-74, 1994

15. Grant GA, Jolley M, Ellenbogen RG, Roberts TS, Gruss JR, Loeser JD: Failure of autologous bone-assisted cranioplasty following decompressive craniectomy in children and adolescents. J Neurosurg 100 (2 Suppl Pediatrics):163-168, 2004

16. Harris DA, Fong AJ, Buchanan EP, Monson L, Khechoyan D, Lam S: History of synthetic materials in alloplastic cranioplasty. Neurosurg Focus 36(4):E20, 2014

17. Häuptli J, Segantini P: [New tissue preservation method for bone flaps following decompressive craniotomy.] Helv Chir Acta 47:121-124, 1980 (Ger)

18. Honeybul S, Ho KM: The current role of decompressive craniectomy in the management of neurological emergencies. Brain Inj 27:979-991, 2013

19. Honeybul S, Ho KM: How "successful" is calvarial reconstruction using frozen autologous bone? Plast Reconstr Surg 130:1110-1117, 2012

20. Honeybul S, Ho KM: Long-term complications of decompressive craniectomy for head injury. J Neurotrauma 28:929-935, 2011

21. Honeybul S, Morrison DA, Ho KM, Lind CRP, Geelhoed E: A randomized controlled trial comparing autologous cranioplasty with custom-made titanium cranioplasty. J Neurosurg 126:81-90, 2017

22. Iaccarino C, Viaroli E, Fricia M, Serchi E, Poli T, Servadei F: Preliminary results of a prospective study on methods of cranial reconstruction. J Oral Maxillofac Surg 73:2375-2378, 2015

23. Inamasu J, Kuramae T, Nakatsukasa M: Does difference in the storage method of bone flaps after decompressive craniectomy affect the incidence of surgical site infection after cranioplasty? Comparison between subcutaneous pocket and cryopreservation. J Trauma 68:183-187, 2010

24. Jasielski P, Głowacki M, Czernicki Z: Decompressive craniectomy in trauma: when to perform, what can be achieved. Acta Neurochir Suppl 118:125-128, 2013

25. Malcolm JG, Rindler RS, Chu JK, Grossberg JA, Pradilla G, Ahmad FU: Complications following cranioplasty and relationship to timing: a systematic review and meta-analysis. J Clin Neurosci 33:39-51, 2016

26. Matsuno A, Tanaka H, Iwamuro H, Takanashi S, Miyawaki S, Nakashima M, et al: Analyses of the factors influencing bone graft infection after delayed cranioplasty. Acta Neurochir (Wien) 148:535-540, 2006

27. Morton RP, Abecassis IJ, Hanson JF, Barber J, Nerva JD, Emerson SN, et al: Predictors of infection after 754 cranioplasty operations and the value of intraoperative cultures for cryopreserved bone flaps. J Neurosurg 125:766-770, 2016

28. Movassaghi K, Ver Halen J, Ganchi P, Amin-Hanjani S, Mesa J, Yaremchuk MJ: Cranioplasty with subcutaneously preserved autologous bone grafts. Plast Reconstr Surg 117:202-206, 2006

29. Paşaoğlu A, Kurtsoy A, Koc RK, Kontaş O, Akdemir H, Oktem IS, et al: Cranioplasty with bone flaps preserved under the scalp. Neurosurg Rev 19:153-156, 1996

30. Pepe MS: An interpretation for the ROC curve and inference using GLM procedures. Biometrics 56:352-359, 2000

31. Polin RS, Shaffrey ME, Bogaev CA, Tisdale N, Germanson T, Bocchicchio B, et al: Decompressive bifrontal craniectomy in the treatment of severe refractory posttraumatic cerebral edema. Neurosurgery 41:84-94, 1997
32. Riordan MA, Simpson VM, Hall WA: Analysis of factors contributing to infections after cranioplasty: a single-institution retrospective chart review. World Neurosurg 87:207213,2016

33. Schoekler B, Trummer M: Prediction parameters of bone flap resorption following cranioplasty with autologous bone. Clin Neurol Neurosurg 120:64-67, 2014

34. Schuss P, Vatter H, Oszvald A, Marquardt G, Imöhl L, Seifert $\mathrm{V}$, et al: Bone flap resorption: risk factors for the development of a long-term complication following cranioplasty after decompressive craniectomy. J Neurotrauma 30:91-95, 2013

35. Schwab S, Steiner T, Aschoff A, Schwarz S, Steiner HH, Jansen O, et al: Early hemicraniectomy in patients with complete middle cerebral artery infarction. Stroke 29:1888-1893, 1998

36. Schwarz F, Dünisch P, Walter J, Sakr Y, Kalff R, Ewald C: Cranioplasty after decompressive craniectomy: is there a rationale for an initial artificial bone-substitute implant? A single-center experience after 631 procedures. J Neurosurg 124:710-715, 2016

37. Scotter J, Iorga R, Stefanou D, Wilson MH: Management of malignant middle cerebral artery infarction following a cardiac stab wound - the role of early decompressive craniectomy. Br J Neurosurg 28:534-535, 2014

38. Shoakazemi A, Flannery T, McConnell RS: Long-term outcome of subcutaneously preserved autologous cranioplasty. Neurosurgery 65:505-510, 2009

39. Sultan SM, Davidson EH, Butala P, Schachar JS, Witek L, Szpalski C, et al: Interval cranioplasty: comparison of current standards. Plast Reconstr Surg 127:1855-1864, 2011

40. Sundseth J, Sundseth A, Berg-Johnsen J, Sorteberg W, Lindegaard KF: Cranioplasty with autologous cryopreserved bone after decompressive craniectomy: complications and risk factors for developing surgical site infection. Acta Neurochir (Wien) 156:805-811, 2014

41. Takeuchi H, Higashino Y, Hosoda T, Yamada S, Arishima $\mathrm{H}$, Kodera T, et al: Long-term follow-up of cryopreservation with glycerol of autologous bone flaps for cranioplasty after decompressive craniectomy. Acta Neurochir (Wien) 158:571-575, 2016

42. Wachter D, Reineke K, Behm T, Rohde V: Cranioplasty after decompressive hemicraniectomy: underestimated surgery-associated complications? Clin Neurol Neurosurg 115:1293-1297, 2013

43. Zingale A, Albanese V: Cryopreservation of autogeneous bone flap in cranial surgical practice: what is the future? A grade B and evidence level 4 meta-analytic study. J Neurosurg Sci 47:137-139, 2003

\section{Disclosures}

The authors report no conflict of interest concerning the materials or methods used in this study or the findings specified in this paper.

\section{Author Contributions}

Conception and design: Carlson, Ernst. Acquisition of data: Ernst. Analysis and interpretation of data: all authors. Drafting the article: Carlson, Ernst. Critically revising the article: all authors. Reviewed submitted version of manuscript: all authors. Approved the final version of the manuscript on behalf of all authors: Carlson. Statistical analysis: all authors. Administrative/technical/ material support: Carlson. Study supervision: Carlson.

\section{Correspondence}

Andrew P. Carlson: University of New Mexico School of Medicine, Albuquerque, NM. andrewcarlson@salud.unm.edu. 